\title{
Overcoming Barriers to Better Heath Outcomes in Patients with Diabetes- Improving and Balancing Patient Education and Pharmacotherapy Initiation
}

\author{
a report by \\ Linda Siminerio, RN, PhD, CDE \\ Director, University of Pittsburgh Diabetes Institute
}

DOI: 10.17925/USE.2008.04.2.42

Despite advances in our understanding of diabetes and the highly effective therapies that are now available, patients are still unable to meet target goals. There are a number of reasons for poor diabetes control that include, but are not limited to: clinical inertia and delayed intensive management; the complexity of diabetes management, which requires time, patient education, and self-management; the attitude of clinicians and patients toward medications; and an outdated acute care approach used in dealing with a chronic disease in our current healthcare systems. In order to overcome the barriers to better health outcomes while improving the balance between patient education and pharmacotherapy, a high-level systems approach to healthcare needs to be addressed. This article will focus on the role of self-management education and its position in pharmacotherapy within the healthcare delivery systems.

\section{Barriers}

It has been reported that only $33 \%$ of adults with type 2 diabetes achieved the American Association of Clinical Endocrinologists (AACE) target of a glycated hemoglobin $\left(\mathrm{HbA}_{1 \mathrm{c}}\right)$ level of $\leq 6.5 \%$. $^{1}$ Even more alarming is that the rate of failure to meet target glucose levels appears to be rising: the proportion of type 2 diabetes patients who failed to achieve the American Diabetes Association (ADA) target of $\mathrm{HbA}_{1 \mathrm{c}}<7 \%$ increased from $55.5 \%$ between 1988 and 1994 to $64.2 \%$ between 1999 and $2000 .^{2}$

Undertreatment of risk factors in patients with type 2 diabetes is also common. The influence of notification of elevated levels of blood pressure,

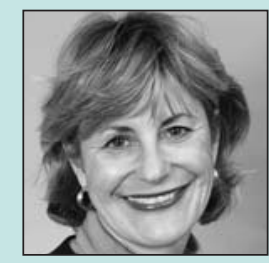

Linda Siminerio, RN, PhD, CDE, is Director of the University of Pittsburgh Diabetes Institute and an Associate Professor at the University of Pittsburgh Schools of Medicine and Nursing. She is a principal investigator on numerous studies related to diabetes prevention and the improvement of care provided by primary care providers, diabetes education, and program development. Recently, she was appointed by Governor Edward G Rendell to advise his Chronic Care Commission, and has been appointed to serve as the organizing Chair for the next International Diabetes Federation (IDF) World Diabetes Congress. Dr Siminerio was President of Healthcare and Education for the American Diabetes Association (ADA) and Senior Vice President of IDF. In these positions, she organized and led national and international efforts on the development of programs, curricula, and standards for diabetes education directed toward healthcare professionals, patients, and the general public. She is a nationally recognized expert on diabetes education and healthcare delivery models and in this capacity organized efforts for the Diabetes Action Plan for Pennsylvania. Dr Siminerio is also working with the US Air Force in implementing models of diabetes prevention and care for the military.

E: simineriol@upmc.edu total cholesterol, and $\mathrm{HbA}_{1 \mathrm{c}}$ on practice has been investigated. ${ }^{3}$ Unfortunately, clinicians do not necessarily translate identification of high-risk factors associated with diabetes to appropriate therapeutic management and effective metabolic control. ${ }^{4,5}$ This failure to act on results and intensify management has been referred to as 'clinical inertia. ${ }^{\prime 6}$

Clinical inertia and delayed intensive management can be attributed to many factors. Diabetes is a complex disease that requires patients to be knowledgeable and able to make daily decisions that affect their health. People with diabetes need to make lifestyle and behavior choices regarding their eating, activity, monitoring, and medication taking. ${ }^{7}$ The complexity of diabetes management requires that health professionals are able to support their patients with the appropriate amount of time, education, and long-term support strategies that are necessary for effective self-management, which includes adherence.

Many patients with type 2 diabetes are seen in a primary care setting, ${ }^{8}$ which presents interesting challenges for the facilitation of intensified therapies. Primary care settings are typically ill-equipped to manage intensive regimens, as they may not have the necessary access to team care and support services. The decision to delay therapy in many cases may be related to fears over inadequate educational resources and added workload. Primary care practices are faced with limited time and resources, as well as matters of reimbursement. ${ }^{9}$

Physician attitudes also play an important role in a patient's willingness to accept and adhere to treatment recommendations. ${ }^{10}$ Many healthcare providers have been known to threaten their patients with therapies that include insulin injections as a penalty for failing to comply with an oral treatment regimen and prefer to delay therapy until it is absolutely necessary. ${ }^{11}$ A physician's perception of patient behavior has been associated with prescription practices. Physicians have been reported to be more willing to delay insulin initiation if they see that their own typical patients are less adherent to their medication or appointment regimens. ${ }^{12}$ Regardless of the reasons for negative attitudes on the part of healthcare providers, they can negatively affect the acceptance of and adherence to therapies of patients.

Patient adherence is an important consideration, and maintaining the burdensome tasks of diabetes management is challenging. Although the data on patient adherence in type 2 diabetes are somewhat limited, especially when considering insulin-taking behaviors, on average the adherence rates for oral medications for type 2 diabetes tend to fall in the $65-85 \%$ range. In some populations, adherence is only $36-54 \% .^{11}$ 
Reasons for poor adherence include patient forgetfulness, schedule disruptions, incomplete instructions, confusion over multiple and complex regimens, concern about side effects, disappointment with symptom relief, and costs.

\section{Team Management}

In a meta-analysis of diabetes quality improvement efforts, those that addressed team changes showed more robust improvements in glycemia than any other strategy. ${ }^{13}$ The unique skill sets that a team brings have been supported in the literature. ${ }^{14,15}$

Perceptions of involvement in diabetes care were examined in the Diabetes Attitudes, Wishes, and Needs (DAWN) survey of physicians, nurses, and patients with diabetes. Only $60 \%$ of the patients with type 2 diabetes reported having all members of the healthcare team in one location. It is unfortunate that for those with type 2 diabetes, fewer than $50 \%$ of patients reported that their healthcare team providers communicated with one another. ${ }^{16}$

Primary care physicians in the survey noted a lack of multidisciplinary care and a need for more support. Nurses reported that they generally provided better education, spent more time with patients, were better listeners, provided support to family, and got to know patients better than physicians. Nurses agreed that a major role for nurses was to provide patients with security and hope, and that they were better able to provide education than physicians. As only one-third of specialist diabetes nurses were performing medication management, nurses and physicians who participated in the study agreed that nurses should take on a larger role in diabetes management. According to the survey, most were willing to embrace more responsibility. ${ }^{17}$

Unfortunately, in this same survey of patients who had better outcomes when they had access to a nurse, fewer than half had access to the services of nurses. ${ }^{18}$ However, although physicians and patients recognize its importance, team management that includes incorporating the roles of a variety of health disciplines, i.e. nurses, dieticians, and pharmacists, is rarely available in primary care.

In the same DAWN study, investigators found that patients who reported better access to healthcare had better diabetes control, better adherence, and lower stress, regardless of their type of diabetes. Furthermore, patients who reported a better relationship with their healthcare professional had better diabetes control, better adherence, and less diabetes distress. ${ }^{16}$ Patients who, in addition to team care, have good support systems-whether from their community, spouse, or children-have been found to take their medications more consistently.

\section{Self-management Education}

It has also been demonstrated that diabetes educators can influence clinical outcomes. Diabetes self-management education (DSME) has been shown to improve the gold standard of diabetes clinical outcomes, i.e. $\mathrm{HbA}_{1 \mathrm{c}}$ levels. Studies have shown as much as a $0.76 \%$ reduction in $\mathrm{HbA}_{1 \mathrm{c}}$ levels in the immediate time-frame after DSME is delivered. As a $1 \%$ decrease in $\mathrm{HbA}_{1 \mathrm{c}}$ is associated with a dramatic reduction in myocardial infarctions, microvascular disease, and death, a $0.76 \%$ reduction can be considered an enormous benefit. The effectiveness of
DSME on $\mathrm{HbA}_{1 \mathrm{c}}$ levels has been directly correlated to the amount of contact time spent between the educator and the patient. Contact time with an educator was the only significant predictor of reduction in $\mathrm{HbA}_{1 \mathrm{c}}$ : 23.6 hours needed for every $1 \%$ absolute decrease in $\mathrm{HbA}_{1 \mathrm{c}}{ }^{18}$ The take-home message is that the more time a patient spends with an educator, the better. $^{21}$

Unfortunately, the benefits of the education interventions on clinical outcomes such as $\mathrm{HbA}_{1 \mathrm{c}}$ levels decrease one to three months later. ${ }^{18}$ This is most likely due to the fact that in order for the DSME intervention to be effective in improving long-term benefits, follow-up is critical. Lack of follow-up could in part be explained by the current poor reimbursement practices for DSME services and, in particular, for follow-up visits. Medicare rules stipulate that only two DSME follow-up visits per patient can be paid for annually.22 Limited payment for visits translates into limited revenue, which ultimately results in a financial risk in supporting an educator's salary.

Unfortunately, the number of patients who receive diabetes education is disappointingly small ${ }^{23}$ due to a number of factors. Access to education has been proposed as a potential barrier, particularly in rural communities where the closest DSME program may be miles away. ${ }^{24}$ Another potential problem may be the traditional way in which education is prescribed and delivered. Currently, physicians are expected to refer diabetes patients to a hospitalbased DSME program. Frequently, patients have many barriers to following through on referrals, including a lack of understanding of the need for the service, distance, scheduling constraints, cultural and language challenges, and reluctance to attend a program in a hospital setting. ${ }^{21,25}$

Integrating Team Care and Education in Community-based Settings-Proven Strategies for Change

Low rates of medication adjustment among patients with levels above the established goal suggest a specific and novel target for quality improvement processes. ${ }^{26}$ It has been demonstrated that the introduction of a multicomponent organizational intervention in the primary care setting significantly increases the percentage of type 2 diabetes and recommended that to be successful, quality improvement change processes should direct more attention to specific clinical actions such as drug intensification and patient activation. ${ }^{27}$

Several programs have demonstrated positive outcomes in facilitating self-management education and team care in community settings. The University of Pittsburgh has successfully implemented the Chronic Care Model (CCM) into its network of primary care practices in western Philadelphia. $23,28,29$ The CCM provides a paradigm shift from our current model of healthcare delivery, which is designed to handle acute problems, to a system that is prevention-based and focused on avoiding long-term problems, including diabetes complications. ${ }^{30}$ The premise of the model is that good-quality diabetes care is not delivered in isolation, but rather with community resources, self-management support, delivery system design, decision support, and clinical information systems working in unison, therefore leading to productive interactions between a proactive practice team and a prepared, motivated patient. ${ }^{14}$

By using the CCM, practices were re-designed to facilitate self-management education within the practice. Diabetes educators were deployed to provide 
DSME on designated diabetes days in primary care offices. Nurse educators were available to provide education and support for newly diagnosed patients and patients undergoing regimen changes and advanced pharmacotherapy. In using the model as a framework, the investigators repeatedly demonstrated that when educators were added to a primary care setting, patients were better able to self-manage and meet treatment goals. $23,28,29$ Given the number of patients with diabetes and the limited amount of time available during a routine office visit, it has been recognized that specialist nurses are underutilized..$^{15,17}$ Davidson et al. demonstrated the benefits of having nurses use therapeutic protocols in managing Hispanic patients in community clinics. They reported significant improvements in process, patient, and cost outcomes. ${ }^{31,32}$

Another community-based diabetes program that has received acclaim is the Asheville Project. The Asheville model is based on the underlying principle that the employer, the employee and a pharmacist can work together to improve diabetes care management while reducing costs. Employers established payment mechanisms that accommodated participating employees with waived co-pays and pharmacist charges for pharmaceutical care services. The employees were made aware of a new, no-cost health benefit and were required to participate in educational visits with the pharmacist. Pharmacists provided health-status monitoring, counseling, medication, and adherence review. The program has been effective in reducing employee sick days, direct medical costs, and $\mathrm{HbA}_{1 \mathrm{c}}$ levels ${ }^{34-36}$ and is being implemented in a number of cities across the US.

\section{Conclusions}

As the diabetes epidemic continues to progress and affect more people, more strategies to help patients meet their targets and lower their risk for diabetes complications are needed. The provision of team care and DSME is critical in overcoming the barriers associated with the skills and complexities of intensified therapies. Challenges such as access to healthcare, poor reimbursement programs, limited training in psychological management, and limited time spent with patients need to be overcome. When these concerns are finally addressed, patients can be educated to handle their complex disease and supported to successfully self-manage.

Healthcare decision-makers and providers responsible for delivering quality diabetes care need to mobilize efforts and explore new avenues to meet the needs of people living with complex chronic diseases. Opportunities to partner with primary care physicians to provide education in their practices, consideration of patient incentives-such as waiving co-paymentsre-visiting reimbursement models for team members, and technological approaches for the creation of virtual teams need to be investigated and supported.

\section{Acknowledgment}

Dr Siminerio is supported in part by funding from the US Air Force administered by US Army Medical Research Acquisition Activity, Fort Detrick, Maryland (award number W81XWH-04-2-0030).
1. American Association of Clinical Endocrinologists. Sate of diabetes in America. Available at: www.aace.com/pub/StateofDiabetes/ DiabetesAmericaReport.pdf (accessed September 6, 2005).

2. Cowie C, Rust K, Byrd-Holt D, et al., Prevalence of diabetes and impaired fasting glucose in adults in the U.S. population: National Health and Nutrition Examination Survey, 1999-2002, Diabetes Care, 2006;29:1263-8.

3. Voorham J, Haaijer-Ruskamp F, Stolk R, et al., The Groningen Initiative to Analyze Type 2 Diabetes Treatment (GIANTT) Group, Influence of elevated cardiometabolic risk factor levels on treatment changes in Type 2 diabetes, Diabetes Care, 2008;31: 501-3.

4. Berlowitz D, Ash A, Hickey E, et al., Hypertension management in patients with diabetes: the need for more aggressive therapy, Diabetes Care, 2003;26:355-9.

5. Grant R, Buse J, Meigs J, The University HealthSystem Consortium (UHC) Diabetes Benchmarking Project Team, Quality of diabetes care in U.S. academic Medical centers: low rates of medical regimen change, Diabetes Care, 2005;28:337-42.

6. Shah B, Hux J, Laupacis A, et al., Clinical inertia in response to inadequate glycemic control: do specialists differ from primary care physicians?, Diabetes Care, 2005;28:600-606.

7. Mulcahy K, Maryniuk M, Peeples M, et al., Diabetes Self-Management Education Core Outcome Measures, Diabetes Educ, 2003;29:768-803.

8. Janes $G$, Ambulatory medical care for diabetes. In: Group NDD (ed.), Diabetes in America, Vol. 95-1468, Bethesda, Maryland: National Institutes of Health, 1995;541-52.

9. Peyrot $M$, Rubin $R$, Lauritzen $T$, $S$ et al., International DAWN Advisory Panel, Patient and provider perceptions of care for diabetes: results of the cross-national DAWN Study, Diabetologia, DOI 10.1007/s00125-005-0048-8, 2005.

10. Anderson R, Fitzgerald J, Gorenflo D, Oh M, A comparison of the diabetes-related attitudes of health care professionals and patients, Patient Educ Couns, 1993a;21:41-50.

11. Rubin $R_{1}$ Adherence to pharmacologic therapy in patients with type 2 diabetes mellitus, Am J Med, 2005;118(Suppl. 5A): 27S-34S.

12. Peyrot $M$, Rubin $R$, Lauritzen $T$, et al., Resistance to insulin therapy among patients and providers: results of the cross-national Diabetes Attitudes, Wishes, and Needs (DAWN) study, Diabetes Care, 2005:28:2673-79.

13. Shojania K, Ranji S, McDonald K, et al., Effects of quality improvement strategies for type 2 diabetes on glycemic control: $A$ meta-regression analysis, JAMA, 2006;296:427-40.

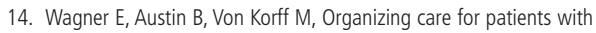
chronic illness, Milbank Q, 1996;74:511-44.

15. Funnell $M$, Peyrot $M$, Rubin $R$, Siminerio L, Steering toward a new DAWN in diabetes management, Diabetes Educ, 2005;(Suppl. 31): $1-18$.

16. Rubin R, Peyrot M, Siminerio L, Health care and patient-reported outcomes: results of the cross-national diabetes attitudes, wishes and needs (DAWN) study, Diabetes Care, 2006;29:1249-55.

17. Siminerio L, Funnell M, Peyrot M, Rubin R, US nurses' perceptions of their role in diabetes care: results of the cross-national diabetes, attitudes, wishes and needs (DAWN) study, Diabetes Educ, 2007;33:152-62.

18. Norris S, Engelgau M, Narayan K, Effectiveness of selfmanagement training type 2 diabetes: A systematic review of randomized controlled trials, Diabetes Care, 2001;24:561-87.

19. Delahanty L, Simkins S, Camelon K, Expanded role of the dietitian in the diabetes control and complications trial: implications for clinical practice, J Am Diet Assoc, 1993;93(7):758-64, 767.

20. Ahern, J, Kruger D, Gatcomb P, et al., The diabetes control and complications trial: the trial coordinator perspective, Diabetes Educ, 1989;15(3):236-41.

21. Peyrot M, Rubin R, Funnell M, Siminerio $L$, Access to diabetes self management education: results of national survesy of patients, educators and physicians, Diabetes Educ, 2009; in press.

22. Pearson J, Mensing C, Anderson R, Medicare reimbursement and diabetes self-management training: national survey results, Diabetes Educ, 2004;30:914-27.

23. Coonrod B, Betschart J, Harris M, Frequency and determinants of diabetes patient education among adults in the U.S. population, Diabetes Care, 1994;17:852-8.

24. Siminerio L, Piatt G, Zgibor J, Implementing the chronic care model for improvements in diabetes care and education in a rural primary care practice, Diabetes Educ, 2005;31:225-34.
25. Peyrot M, Rubin RR, Access to diabetes self-management education, Diabetes Educ, 2008;34(1):90-97.

26. Peterson $\mathrm{K}$, Radosevich $\mathrm{D}, \mathrm{O}^{\prime}$ Connor $\mathrm{P}$, et al., Improving diabetes care in practice: findings from the TRANSLATE trial, Diabetes Care, 2008:31:2238-43.

27. O'Connor J, Sperl-Hillen J, Pronk N, Murray T, Primary care clinic-based chronic disease care, Dis Manag Health Outcome, 2001;9: 691-8.

28. Piatt $\mathrm{G}$, Orchard T, Emerson $\mathrm{S}$, Siminerio L, et al., Translating the chronic care model into the community: A randomized controlled trial of a multifaceted diabetes education intervention, Diabetes Care, 2006;29:811-17.

29. Siminerio L, Piatt G, Emerson S, et al., Deploying the chronic care model to implement and sustain diabetes self-management training programs, Diabetes Educ, 2006;32:1-8.

30. Bodenheimer $\mathrm{T}$, Wagner $\mathrm{E}$, Grumbach $\mathrm{K}$, Improving primary care for patients with chronic illness: the chronic care model, Part 2, J Am Med Assoc, 2002;288:1909-14.

31. Davidson M, The effectiveness of nurse-and pharmacist-directed care in diabetes disease management: A narrative review, Curr Diabetes Rev, 2007;3:280-86.

32. Davidson $M$, Effect of nurse-directed diabetes care in a minority population, Diabetes Care, 2003;26:2281-7.

33. Fera T, Bluml B, Ellis W, et al., The Diabetes Ten City Challenge: Interim clinical and humanistic outcomes of a multisite community pharmacy diabetes care program, J Am Pharm Assoc, 2008;48: 181-90.

34. Cranor C, Christensen D, The Asheville Project: short-term outcomes of a community pharmacy diabetes care program, J Am Pharm Assoc, 2003;43:149-59.

35. Cranor C, Bunting B, Christensen D, The Asheville Project: long-term clinical and economic outcomes in a community pharmacy diabetes care program, J Am Pharm Assoc, 2003;43: 173-84.

36. Garrett D, Martin L, The Asheville Project: participants' perceptions of factors contributing to the success of a patient selfmanagement program for diabetes, J Am Pharm Assoc, 2003;43: 185-90. 


\section{Diabetes Educators: \\ Your Partners in Diabetes Management}

Diabetes Educators are healthcare professionals who focus on helping people with diabetes understand their disease and learn how to adjust their lifestyle and behavior so that they can develop self-management skills. Many are also Certified Diabetes Educators (CDEs) which means they have met additional criteria for providing diabetes care.

Diabetes Educators provide comprehensive care. They counsel patients on how to incorporate healthy eating and physical activity into their lives. They also help them understand how their medications work, teach them how to monitor their blood glucose to avoid the risk of complications, and enable them to problem-solve and adjust emotionally to diabetes.

Diabetes Educators are an integral member of the diabetes care team. They make your job easier by ensuring that your patients understand their disease and are physically, socially, and psychologically able to set and realize their selfmanagement goals. The result is improved clinical outcomes for your patients with diabetes.

\section{To learn more and to locate an educator in your area, go to www.diabeteseducator.org.}
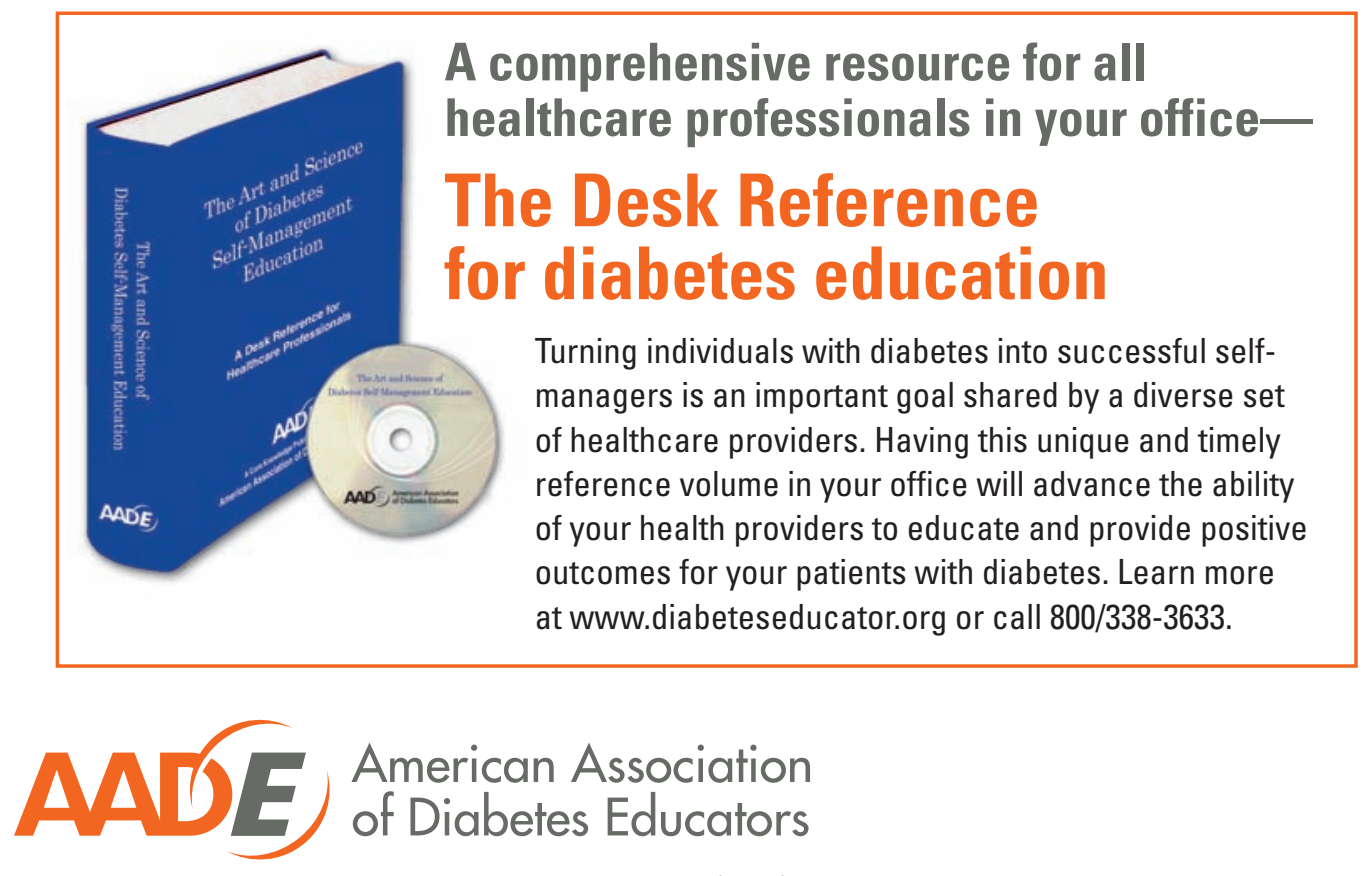

The American Association of Diabetes Educators (AADE) is a professional membership organization dedicated to driving professional practice to promote healthy living through self-management of diabetes and related conditions.
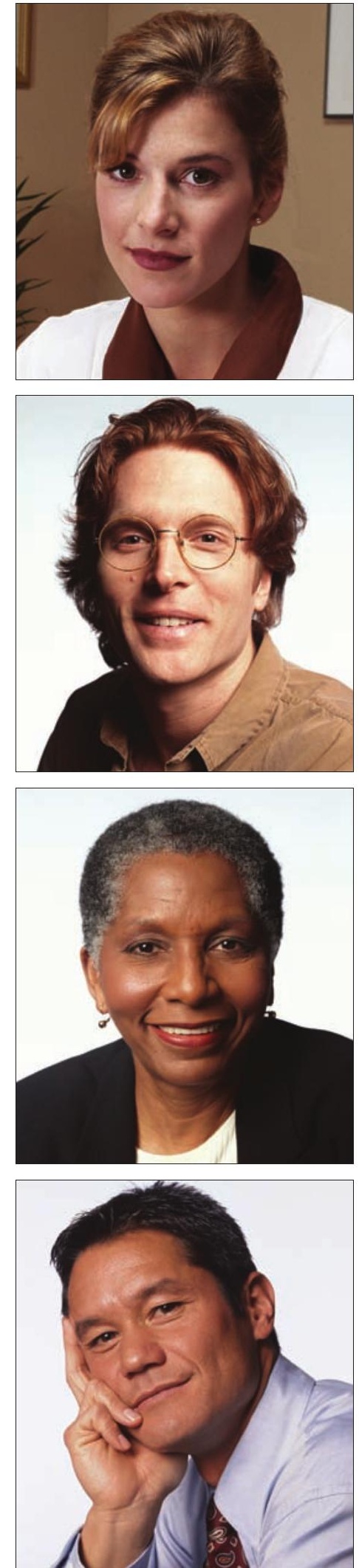